\title{
Nostalgia of Time and Return of Space: An Analysis of the Artistic Dimensions of Oates' Early Novels
}

\author{
A'na Zhang ${ }^{1,2}$ \\ ${ }^{1}$ Center for Foreign Literature and Culture, Guangdong University of Foreign Studies, Guangzhou, Guangdong, China \\ ${ }^{2}$ General Education Department, Southern Medical University, Guangzhou, Guangdong, China
}

\begin{abstract}
Joyce Carol Oates' early novel art is represented by the tetralogy of Wonderland. As a representative writer of "psychological realism", she dissolves the character consciousness with dialogue characteristics into time and space. Oates constructed a nostalgic time and homecoming space, which showing the cultural landscape of the 1960s' in the United States.
\end{abstract}

Key words: Joyce Carol Oates; Wonderland tetralogy; time; space

\section{Introduction}

Joyce Carol Oates is an important contemporary American female writer, and she has been working hard until now. Her early artistic creation is represented by four parts, including the novel A Garden of Earthly Delights (1967), Expensive People (1968), Them (1969), and Wonderland (1971). Oates clearly stated in her 1999 essay, "But by 1971, the trilogy became a tetralogy: Wonderland ended this informal series thematically. And timely transcend the era of the theme, and enter the unmarked era of enlightenment from the United States in the late Vietnam War." A Garden of Earthly Delights won the Rosenthal Award of the National Academy of Letters and Arts in 1968, and was later included in the British Verrag Classic series. Expensive People, Them and Wonderland won the most important literary awards in the United States---the National Book Award in 1969, 1970, and 1972 respectively.

The artistic vision and focus of the tetralogy of Wonderland lies in the fact that the consciousness of the protagonist has acquired the status of the subject just like the characters. In the work, she constructs a large-scale dialogue through the main character's consciousness, expressing her views on the world calmly and freely. In art, Oates attaches great importance to the characteristics of time and space, dissolving her own in-depth experience in the grand space-time background, and obtains the nostalgia in time and the aesthetic direction of returning to the homeland in space.

\section{The Nostalgia of Time}

Oates focuses on drawing on the artistic skills of stream-of-consciousness novels, as well as the characteristics of time and place in the novel. She combined the intuition of psychological realism with thorough social and historical analysis, which is one of the reasons why Oates is regarded as a writer of "psychological realism". As she mentioned, "The essence

Copyright (C) 2021 by author(s) and Frontier Scientific Research Publishing Inc.

This work is licensed under the Creative Commons Attribution International License (CC BY 4.0).

http://creativecommons.org/licenses/by/4.0/ 
of place and time. The personal self is magically combined with the larger, public, mysterious, and unknowable spirit."

Oates has clear and objective time clues in the four parts. This avoids completely pushing the characters to the extremes of mental consciousness activities, and is convenient for connecting the background of the times to show the life and spiritual world of the protagonist, and also makes the activities of the objects more concentrated. Expensive People begins its narrative when the Richard family came to Fenwood, "So, when I begin to disintegrate, let us set the date at will as January 20, 1960.” Until Richard went out with a gun three times, “This is a pleasant night---July 23, 1960.” The entire book is condensed in about half a year.

Time will also drive the protagonist's limited perspective to move. For example, in Them, the three characters of Loretta, Jules, and Maureen are interspersed to show the clues of time. From the first section of the first chapter, "August 1937" in front of the young Loretta mirror from the beginning of the stand, to the end of Maureen, who was completely awakened from autism in "August 1967", the time has spanned thirty years, and the three narrative perspectives intertwined and jumped. Life becomes a circle, encompassing characters, showing the similarities and differences in the trajectory of destiny. Oates uses specific time to highlight the background of the era, and the characters retreat and merge into the era set by the author. The emphasis on time is more prominent in Wonderland. The novel starts with the murder of Jesse's family in the first section of chapter 1: It was December 14th, 1939. The last section of Chapter 2 has a linear development until October 1956, a week before Jesse's 31st birthday. Then time showed a leaping back and forth. From Shelly's letter to Jesse in 1970, the time went back to "November 22, 1963". After the news of President Kennedy's assassination was interspersed, time jumped to 1970. The jump in time implies that Shelly took drugs and ran away from home, and her health was deteriorating. In the transfer of time sequence, there is a return of recalling time and forming time. The view on time is expressed in the novel Wonderland: "Every day passes by like this. Time itself is an entity. It takes them forward, saying goodbye to the past, and moving forward forever." "Time will also move forward." "This separation allows certain events to happen......Time is restored; normal life begins again." "There is a gap in the giant current of time......But time is restored." "What is time? An element. He lives in these elements, living involuntarily...... And between the two is an endless time."

Bergson once compared the extension of everything to "a bottomless, bankless river, which does not flow in an uncertain direction by the force that can be marked." Only with the help of extension, can we expand ourselves infinitely and realize the eternity of life. Time is an entity, an element of life, and the line of self-awareness, memory experience, and emotional will deep in the character's heart. Oates, who is so mixed with past experiences, transcends the one-way surface of time or consciousness, wandering freely between the past and the present. As she said: "All writers are time travelers. The time she transcends is not just the 'now' and the 'past', because memory is a transcendental function." Oates is like a troubadour, introducing objective time into the work and blending. In order to learn from her own inner experience, she hovered on the "corridor of time". This is how Oates unveiled the broad picture of American society in the rhythm of art.

\section{The Return of Space}

Oates mentioned the importance of location more than once. "I am a writer who is completely fascinated by places; my writing is more of a way to calm homesickness, and setting my character's place of residence is very important for me and the character itself." Most of the locations in Oates' novels are based on her hometown Lockport and Detroit. $A$ Garden of Earthly Delights is set in various parts of the American countryside and western New York. Expensive People is set in the affluent suburb of Detroit called Fernwood. The background of Oates' early novels described the American countryside "Eden County" in a richly lyrical way, which has a non-negligible connection with the "Erie County" where she lived in her early years. Beginning with Them, Oates began to shift her vision from rural to urban. Looking at the 
reality and fiction of the locations in the four parts, the protagonist is combined with the face of the times. "I think that the 'regional sense' is very important to me. Writing itself entrusts nostalgia, and carries your memory of a place and a period of time. When we create, we go back to the past and create a space for imagination for the lost world."

Oates builds a visualized space of daily life by using magazines, movies, advertisements, stars, cars, etc. that represent mass consumption culture. Clara named Swann from the movie star Robin in the movie magazine. In the novel Expensive People, there are authentic magazines and writers in American society and culture. For example, magazines that have appeared around Nada include "Scientific American" and "Reader's Digest". Richard also envisaged the comments made by the outside world after the publication of his work Expensive People, which is the "true" supplement that Richard claimed. These include New York Times Book Review, Time, The New Republic and so on. There are also "famous" comments by the fictitious critic Hanley Stuart Hingham. Other magazines include The Trans American Review, books Recent \& Readable, Literature \& Classics and so on. In order to achieve a real effect, the author also used notes to illustrate. Richard also found the novel The Molesters written by Nada in The Quarterly Review of Literature. The author seems to have created a "real world", but Richard noted in the first note: "When I read this, this naive performance gave me a very bad impression, but I have to bear it. These experiences exist, reality exists, but how to get it? Everything I typed becomes a simple lie, because it is not true." Richard's notes are more like a "glance" of thinking in the author's creation. It is difficult to distinguish between the protagonist and the author in the intercourse of daily experience. Almost many men in the four parts have dreamed of having a car. For example, Carlton bought a car to find Clara who had run away; Laurie drove Clara to escape; Richard's father and mother had two cars: a yellow Cadillac and Lincoln; Jules worked as Bernard's driver and then drove a small truck to deliver flowers; in Wonderland, Dr. Peterson gave him a car in order to reward Jesse for admission to college. The car is a symbol of wealth and status. With a car, you can even go where you want to go, which represents a kind of freedom. These key words of mass consumption culture gradually increase in the order of the creation time of the tetralogy. Oates' introduction of the social level has gradually enriched and opened up.

There is also a category of news, briefings, photos, letters, etc. that resemble news clips. Them interspersed with news similar to news clips in the novel, violent incidents in newspapers and other news, violent news flashing in the flow of character consciousness, and violent episodes in the dialogue between the characters and the characters. The "fragments" of violence in Them, such as Howard's radio wafting news about war; the newspaper in his hands on deaths; family members discussing violent news at the dinner table; The dialogues of Loretta and his girlfriend, Betty, and Zhu Paul shed light on the frequent violent incidents in society: the story of a woman in a lunatic asylum being pregnant; the story of Betty fooling around with black people, and so on. Therefore, readers wrote to the author, asking Oates to replace the interesting talk. When the novel won the National Award in 1970, it was called a "real" work by critics. From this perspective, Oates' superb creative skills can be seen. Similarly, in Wonderland, Dr. Peterson's five-hundred secret book of fate are filled with violent murders.

The third type of image is the surname, concept, uncertainty of the flow of consciousness, smell, label, etc. Sometimes using a sentence of the character at that time, a conscious activity, a statement of previous facts, a replay of a picture segment, a replay of an emphatic word, and a sound segment are interspersed repeatedly. These images in daily life are displayed through the reproduction of the protagonist's conscious activities. "Not only the reality of the protagonist, but also the external world and daily life around him are absorbed into the process of self-consciousness, from the perspective of the writer to the field of vision of the protagonist." In Expensive People, the smell of Richard's mother's luggage occupies an important position in his consciousness. The sensitive "taste" of his passing luggage has become a very important image in his memory. As long as this image appears, it means that the mother is about to leave. "If there is any 
'news' in her works, it lies in the unquestionable and direct atmosphere and details of contemporary life. This is combined with her calm artistic skills to bring the terrible aspects of American life to life. Readers show it vividly." The audio-visual fragments in daily life have achieved integration with social history through self-awareness amplification.

\section{Time Extends Space, Space Highlights Time}

In the point of Oates' view, the deep experience of time, space and oneself is a "trinity". Time and space reside in deep experience, time clarifies history naturally, and emotional experience in space is supplemented by inheritance. Oates uses daily images to form a world parallel to the protagonist's daily life in her works, which reflects the world in the eyes of the author as a whole. Through the use of these images in daily life, not only the maneuver over time is realized, but also the unique crystallization point of the era culture at the symbiosis level is advantageously displayed. Oates' use of this technique gives the novel a strong sense of reality, which is mixed in the protagonist's memories of the past. Oates's mystery of merging the individual with the universe, that is, the helplessness of integrating people into social history as individuals. "The essence of artistic image is like this: we are both inside and outside, we can live inside it, and observe it from the outside. The essence of artistic cognition is that this is a dual experience and observation: The life of the other---it is mine and not mine."

\section{Conclusions}

Based on Oates's writing, extending in the time of history, from the relationship between the individual's inner world and the outer world, the individual's questioning of family, history, and society, finally enters the individual's inner world completely and makes social history disappear. Among the individuals, through this artistic creation of integrating the fate of different characters into the symbiosis level, a vertical and horizontal two-way dimension is obtained.

\section{Conflicts of Interest}

The author declares no conflicts of interest regarding the publication of this paper.

\section{Acknowledgments}

This work was supported by the Youth Innovative Talents Project under Guangdong Provincial Department of Education (Humanities and Social Sciences) 2017WQNCX015.

\section{References}

[1] Bakhtin M. (2013). Problems of Dostoevsky's poetics. University of Minnesota Press.

[2] Bergson H. (1999). Duration and simultaneity: Bergson and the Einsteinian universe. Clinamen Press.

[3] Johnson G. (1998). Invisible Writer: A Biography of Joyce Carol Oates. Dutton.

[4] Oates J. C. (2009). A garden of earthly delights. Modern library.

[5] Oates J. C. (2006). Expensive people. Random House USA Incorporated.

[6] Oates J. C. (1974). New Heaven, New Earth: The Visionary Experience in Literature. Vanguard Press, New York.

[7] Oates J. C. (2000). Them. Random House Digital, Inc.

[8] Oates J. C. (2009). The faith of a writer: Life, craft, art. Zondervan.

[9] Oates J. C. and Tobias W. (2013). Where Are You Going, Where Have You Been? Difusión, Centro de Investigación y Pubicaciones de Idiomas.

[10] Oates J. C. (2011). Wonderland. Modern Library. 